\title{
How I do it: judging appropriateness for TTE and TEE
}

\author{
Ricardo Fonseca and Thomas H Marwick
}

\begin{abstract}
The increasing cost of healthcare is a widespread international problem to which the cost of imaging has been an important contributor. Some imaging tests are ordered inappropriately and contribute to wasted use of resources. Appropriate use criteria have been developed in the USA in order to guide test selection, but there are a number of problems, including the evidence base for these criteria and the steps that can be taken to change physician practice. A restrictive approach to test ordering is difficult to fit to the nuances of clinical presentation and may compromise patient care. We propose an alternative approach to physician guidance based on the most common markers of inappropriate testing.
\end{abstract}

Keywords: Appropriate use, Transthoracic echocardiography, Transoesophageal echocardiography

No management decisions in medical practice are exempt from a concept that is difficult to measure: appropriateness. In common parlance, an appropriate choice is one that which is suitable or proper in the circumstances, but this is surprisingly different from the medical definitions. The concept of appropriateness defined by the RAND/UCLA methodology in the 1980's was the cornerstone for developing the first attempt at appropriate use criteria (AUC). That concept suggested that "an appropriate procedure in one in which the expected health benefit (e.g, increased life expectancy) exceeds the expected negative consequences (e.g., mortality, morbidity, anxiety, pain, time lost from work) by a sufficiently wide margin that the procedure is worth doing, exclusive of cost" [1,2].

The adaption of this concept to cardiac imaging led to an appropriate test being defined as "one in which the expected incremental information, combined with clinical judgement, exceeds the expected negative consequences (risks of the procedure i.e. radiation or contrast exposure and the downstream impact of poor test performance, such as delay in diagnostic (false negatives) or inappropriate diagnosis (false positives)) by a sufficiently wide margin for specific indication that the procedure is generally considered acceptable care and a reasonable

\footnotetext{
* Correspondence: Tom.Marwick@utas.edu.au

Menzies Research Institute Tasmania, 17 Liverpool St, Hobart, Tasmania 7000, Australia
}

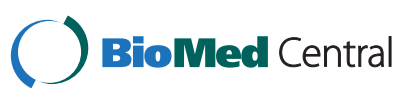

(c) 2014 Fonseca and Marwick; licensee BioMed Central Ltd. This is an Open Access article distributed under the terms of the Creative Commons Attribution License (http://creativecommons.org/licenses/by/4.0), which permits unrestricted use,

distribution, and reproduction in any medium, provided the original work is properly credited. The Creative Commons Public Domain Dedication waiver (http://creativecommons.org/publicdomain/zero/1.0/) applies to the data made available in this article, unless otherwise stated. approach for the indication" [3]. Because of the low risk of imaging, there are many circumstances in where this definition seems to be insufficient - the risk is almost zero so the balance of benefit and risk is positive, but the information obtained is still inadequate to justify performance of the test. A new definition overcomes these concerns by framing the decision in the context of a consensus about "reasonable care" [4], and resource utilization "The concept of appropriateness, as applied to health care, balances risk and benefit of a treatment, test, or procedure in the context of available resources for an individual patient with specific characteristics" [5]. Importantly, it is now acknowledged that AUC should provide guidance to supplement the clinician's judgment, rather than being prescriptive.

\section{Motivations to the definition of appropriate use criteria}

While the risk of harm with inappropriate intervention was an important motivator to the application of AUC, the focus on appropriate use in imaging is mainly rooted in resource utilization and medical expenditure. The contribution of imaging to the medical budget started to be highlighted in the United States $>20$ years ago. At this time, the Medicare Payment Advisory Commission (MedPAC) showed a 10\%/year increase of spending for cardiac imaging between 1999 and 2002, when the average growth per year of all services was $5.2 \%$ [6]. This

ricle, unless otherwise stated. 
continued throughout the following decade - imaging payments to Cardiologists in 2000 were US $\$ 1.6$ billion, increasing to US $\$ 5.1$ billion in 2006 [7]. Contributors to this growth included the rapid proliferation of imaging machines, limited experience with new imaging modalities among non-specialists, automated referral pathways, poor quality of imaging (requiring repetition) and defensive medicine [8]. Differences in the use of imaging among regions supported the contention that the selection of imaging test was discretionary rather than diseaserelated [9-11] (Figure 1).

\section{Development and application of appropriate use criteria}

One of the responses to the overuse of imaging was the development of AUC. The American College of Cardiology Foundation (ACCF) along with other medical associations formed the Appropriateness Criteria Working Group (now called ACCF AUC Task Force) [4], which used a modified RAND/UCLA methodology $[1,2]$ to elaborate the criteria. After the review of possible indications, an expert rating panel determined if an indication was appropriate, uncertain or inappropriate (now called appropriate, may be appropriate and rarely appropriate by the new methodology) $[3,4]$.
The first AUC (for SPECT) were launched at the end of 2005 and the first transthoracic (TTE) and transesophageal (TEE) echocardiography AUC document was released two years later [12,13]. Stress echocardiography (SE) was not included in the first version of the echocardiography AUC [14], but these criteria were merged in the 2011 version [15]. The AUC continue to evolve, and criteria for multimodality cardiac imaging and the redefinition of "inappropriateness" represent recent changes $[4,16]$.

While the AUC have become a cornerstone of the efforts to improve quality in the USA, their uptake in other jurisdictions has been less enthusiastic. The current criteria have a number of disadvantages [17-43];

1) The AUC have been defined by consensus. The scientific basis of some AUC is weak, with level of evidence $\mathrm{B}$ or $\mathrm{C}$.

2) AUC represent a compilation of indications but not all situations in which an echocardiogram could be performed are addressed. Although some studies of AUC indicate all tests to have been classified $[18,19,25,31,32,37,38]$, in reality, several indications are often present in the same patient. Retrospective audit may be especially problematic, as the reason

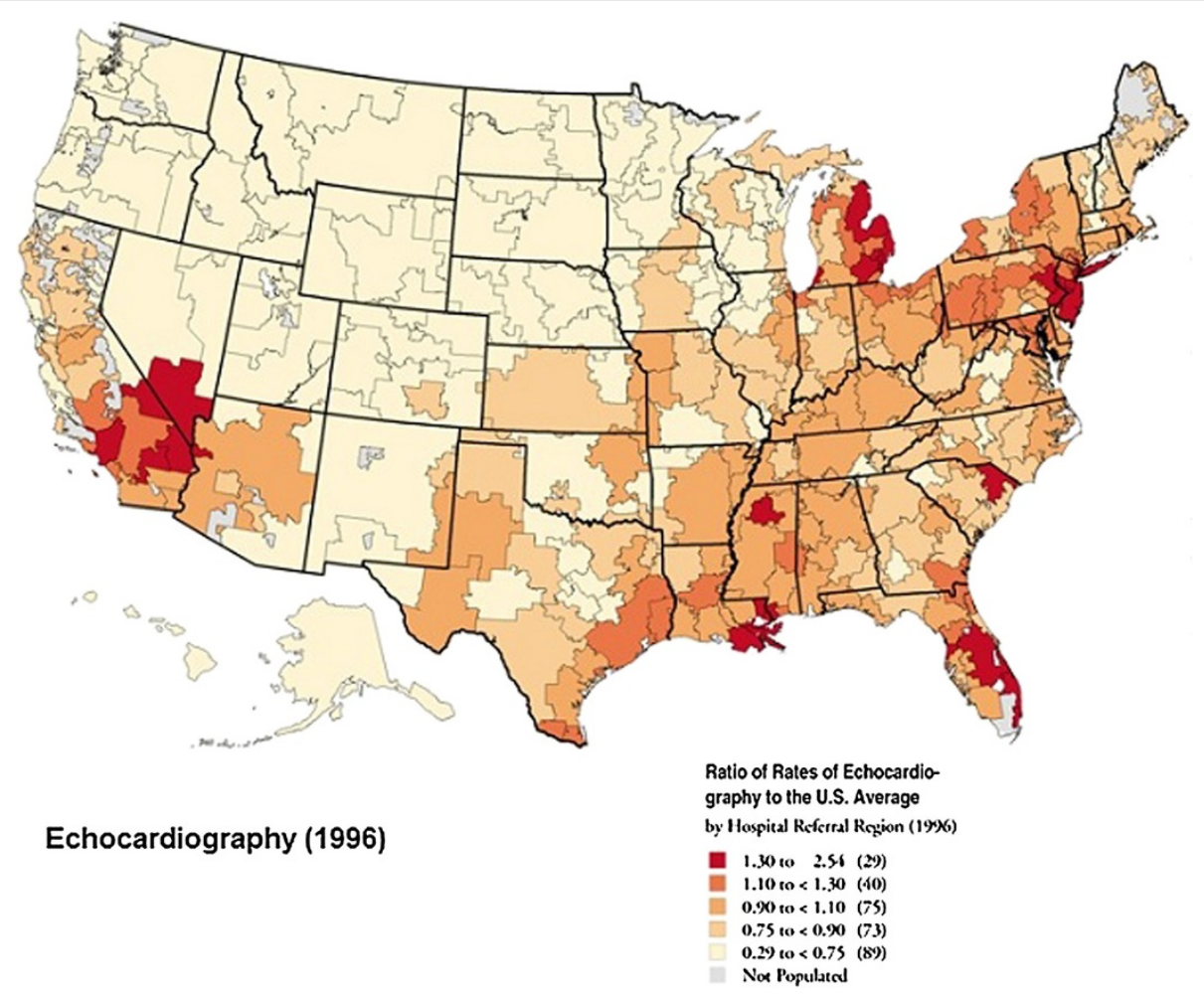

Figure 1 Differences in the use of echocardiography in the US in 1996. Regional variations by hospital referral region, expressed as a ratio to the US average. From Wennberg D, et al. The Dartmouth Atlas of Cardiovascular Health Care. P65. 1999 [11]. 
for requesting an echocardiogram is often inadequately detailed in the medical records.

3) Conversely, several recommendations for echocardiography in current practice guidelines (not just in echocardiography but for disease entities) lack counterparts in the AUC. For example, a class I recommendation is given for follow-up or surveillance after surgery of masses known to have a high likelihood of recurrence (eg myxoma [44]). The AUC classification of "suspected cardiac mass" - or even screening - does not cover the described scenario.

4) The application of AUC to patient selection may be problematic as an audit tool. When an appropriate indication is required to order the test at point-ofservice, the referring clinician may list a co-existing appropriate indication rather than the actual clinical problem (which may be of inappropriate). This is particularly likely when the proportion of inappropriate tests is assessed as part of the echocardiography accreditation process.

After 7 years of using the AUC for echocardiography (TTE and TEE), there are concerns about the real impact of the AUC on physician ordering behaviour [45]. The literature seems to show a similar proportion of inappropriate testing, in spite of experience, educational campaigns and close follow-up. Moreover, the correlation between appropriateness and clinical impact has not been well studied [31].

\section{Application of AUC in daily practice}

We do not favour the use of AUC as a "gatekeeper" to echocardiography. Rather, we see the AUC provide a yardstick to permit three means of improving appropriateness education, guidance at point-of-care and laboratory-based audit;

i). Education: Although educational interventions seem to be a logical approach, the results of heterogeneous attempts have been contradictory. On the one hand, for instance, an educational campaign consisted in lectures, a pocket card with the AUC and feedback showed encouraging results as one of the successful tools for improving appropriateness [23]. On the other hand, similar projects focused in physician education and feedback $[46,47]$, did not show improvement. The AUC are an excellent starting point in this respect. Essential parts of educational campaigns include lectures, pocket cards and feedback.

ii). Control in point-of-care: The use of prior authorisation protocols through a Radiology Benefit Manager (RBM) is widely used to control access to expensive tests of limited availability, such as positron emission tomography and cardiac magnetic resonance, although its efficiency and effectiveness have been questioned [47]. The use of AUC at point of care involves ordering physicians in the attempt to decrease inappropriate tests. In order to facilitate this, friendly electronic tools have been invented to help clinicians to choose "appropriately" at the point-of-order [24]. Recent work has proposed that this practice is of equivalent efficacy to the use of the RBM [48], with greater efficiency and better preservation of the autonomy of the attending physician. Incorporation with an electronic ordering process can inform the clinician about appropriateness when the test is requested. The risk of both AUC and RBM are that other appropriate (but inactive) clinical problems that can be used to have a test approved to address an inappropriate question.

iii). Laboratory-based audit: We have focused on this because of the limitations of the above two methods. Laboratories are potentially more motivated than requestors because of the reputational and economic risk of high levels of inappropriate use. While we acknowledge that the audit process can be problematic in private practice, as the locus of control is with the referring doctor, it is important to consider that the laboratory will be held responsible for the performance of inappropriate tests and the consequence of more inappropriate tests will be less reimbursement. In this setting, it seems likely that some investment into auditing this process will be reasonable. Inevitably, urgent echocardiograms and communication problems represent scenarios where the process is challenging, but if appropriateness is to be audited, we would suggest that defining the "at risk" study for inappropriateness (see below) is a means of improving the efficiency of this process from needing to audit $100 \%$ of requests to audit of the $\sim 15 \%$ of requests that are included in this list. The additional scrutiny given to these requests does not necessitate individual contact with the referring physician in all cases.

\section{Screening imaging requests for appropriateness}

If the strategy of laboratory-based audit is selected, a simple screening process is required for the thousands of requests which are submitted to the laboratory every year. Our approach has been to base this around the indications which generate the greatest numbers of inappropriate tests in the 2011 AUC for echocardiography (TTE and TEE, but not including stress, Figure 2) 


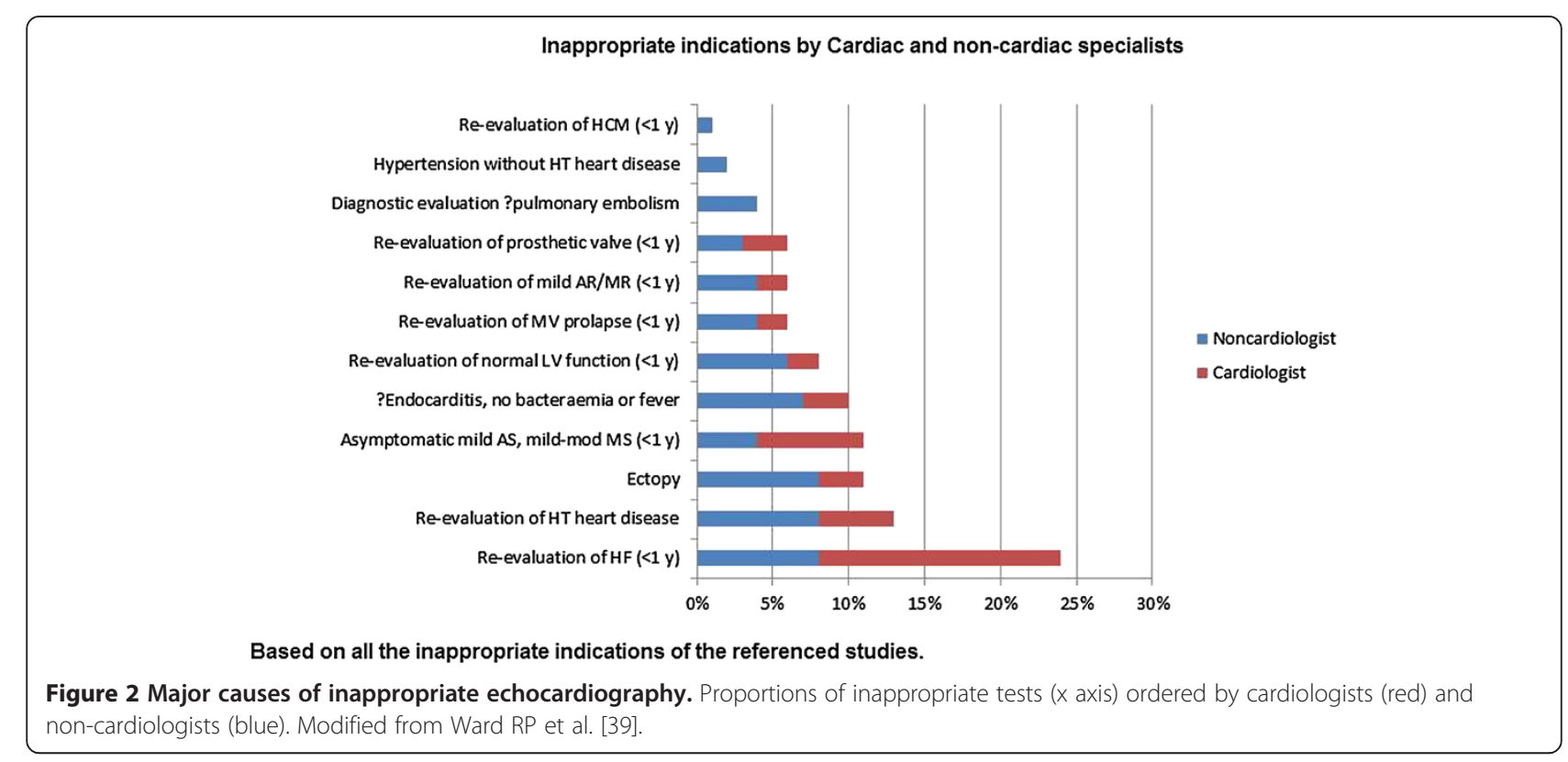

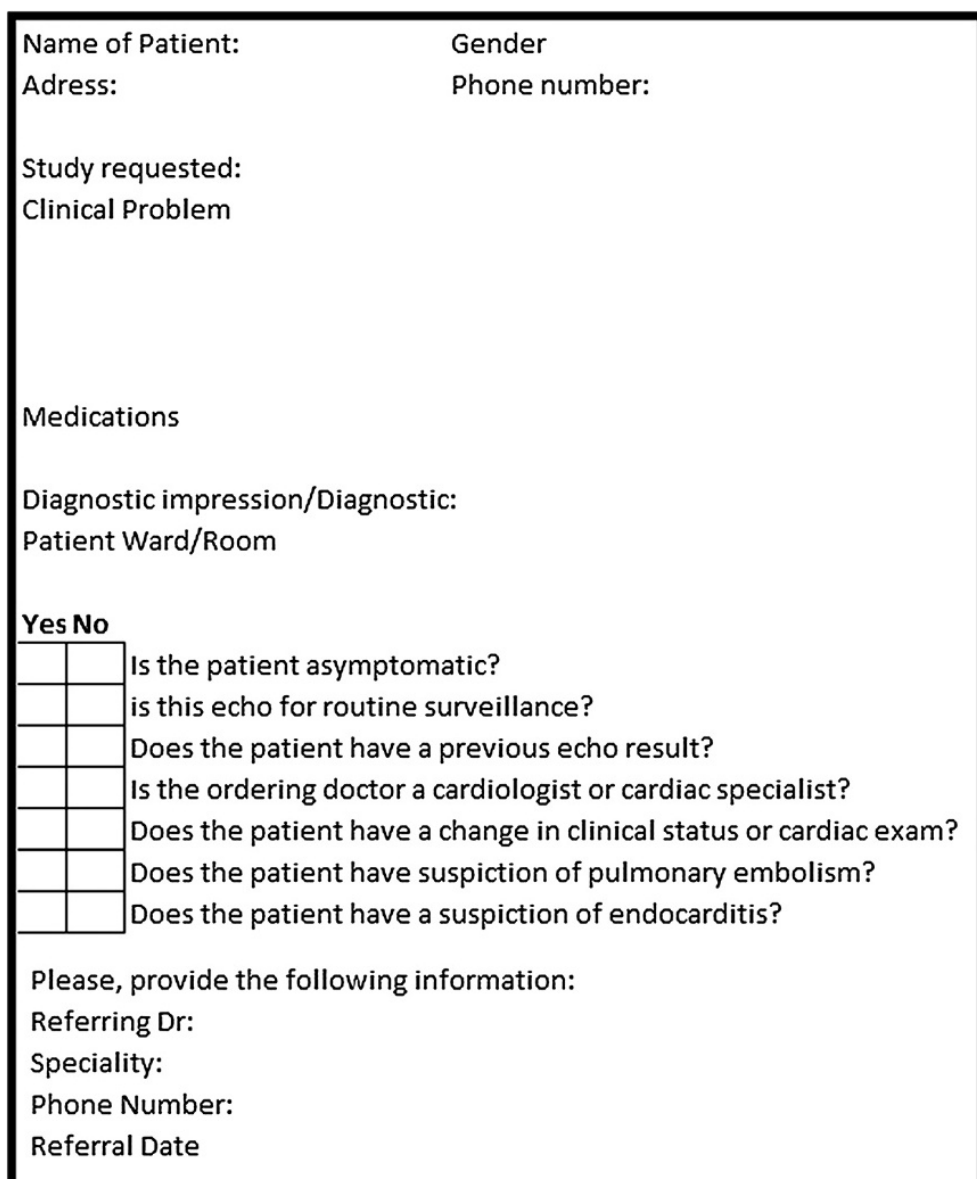

Figure 3 Proposed checklist to discriminate possible inappropriate orders. A simplified check-list to be reviewed at point of service, as a prompt to seeking clarification from the referring physician. 
[15]. These are related to routine surveillance, evaluation of symptoms without other symptoms/signs of cardiac disease and low pretest probability of endocarditis $[18,20,21,23,33,34,36,41]$. Other situations include a suspicion of pulmonary embolism, when the exam would not change management, and when a test is ordered by non-cardiologists.

Routine surveillance is the most common inappropriate indication for TTE. The most common situations of inappropriate repeat imaging of ventricular function include assessment in patients with known CAD and no change in clinical status or cardiac exam [34,41], systemic hypertension without symptoms or signs of hypertensive heart disease [20], and within a year of previous testing in heart failure (systolic or diastolic) when there is no change in clinical status or cardiac exam $[20,34])$. A very common situation in patients with nonspecific symptoms includes patients with lightheadedness/presyncope without other symptoms) [23,41]. Common valverelated indications include $<3$ year after prosthetic valve implantation in the absence of known or suspected valve dysfunction [33], and evaluation of infective endocarditis when there is transient fever without evidence of bacteremia [23] or new murmur or transient bacteraemia with a pathogen not typically associated with endocarditis. For transoesophageal echocardiography, the most common inappropriate indications are related to endocarditis with low pretest probability and routine use of TEE when a diagnostic TTE is reasonably anticipated to resolve all concerns [21].

The availability of this information on the characteristics of inappropriate tests has enabled the development of a checklist to identify studies where a discussion regarding the merits of testing can be initiated from the laboratory (Figure 3).

\section{Conclusions}

Judging appropriateness in echocardiography is a process based on knowledge, experience, information, resources and the real desire to provide an adequate service to the patient. It does not sit well with formulaic approaches based on uncritical application of AUC. Importantly, it is now acknowledged that AUC should provide guidance to supplement the clinician's judgment, rather than being prescriptive [5].

Although the audit process described above helps to strengthen the application of the AUC, it is difficult to control the problems associated with self-referral and the veracity on the part of ordering physicians. In our opinion, the optimal approach requires dialogue between treating physicians, cardiologists and sonographers. The perfect tool has not yet been designed, but a process that flags discussion at the point of imaging may be more effective than a gatekeeper at the point of ordering the test.

\section{Abbreviations}

ACCF: American college of cardiology foundation; AUC: Appropriate use criteria; CAD: Coronary artery disease; MedPAC: Medicare payment advisory commission; RAND/UCLA: RAND corporation/university of California Los Angeles; RBM: Radiology benefit manager; SE: Stress echocardiography; SPECT: Single photon emission computed tomography; TTE: Transthoracic echocardiography; TEE: Transesophageal echocardiography.

\section{Competing interests}

The authors declare that they have no competing interests.

\section{Authors' contributions}

RF; contributed to conception/design, gathered and interpreted data and wrote the paper, approved final version and agrees to be accountable for content. THM; contributed to conception/design, gathered and interpreted data, edited the paper, approved final version and agrees to be accountable for content.

Received: 20 March 2014 Accepted: 5 June 2014

Published: 24 June 2014

\section{References}

1. Fitch K, Bernstein S, Aguilar MD, Burnand B, La Calle JR, Lazaro P, Loo M, McDonnell J, Vader JP, Kaham JP: The RAND/UCLA Appropriateness Method user's manual. Santa Monica (CA): RAND Corporation; 2001.

2. Brook RH, Chassin MR, Fink A, Solomon DH, Kosecoff J, Park RE: A Method for the Detailed Assessment of the Appropriateness of Medical Technologies. Int J Technol Assess Health Care 1986, 2(01):53-63.

3. Patel MR, Spertus JA, Brindis RG, Hendel RC, Douglas PS, Peterson ED, Wolk MJ, Allen JM, Raskin IE: ACCF proposed method for evaluating the appropriateness of cardiovascular imaging. J Am Coll Cardiol 2005, 46(8):1606-1613.

4. Hendel RC, Patel MR, Allen JM, Min JK, Shaw LJ, Wolk MJ, Douglas PS, Kramer CM, Stainback RF, Bailey SR, Doherty JU, Brindis RG: Appropriate Use of Cardiovascular Technology 2013 ACCF Appropriate Use Criteria Methodology Update: A Report of the American College of Cardiology Foundation Appropriate Use Criteria Task Force. J Am Coll Cardiol 2013, 61(12):1305-1317.

5. Carr JJ, Hendel RC, White RD, Patel MR, Wolk MJ, Bettmann MA, Douglas P, Rybicki FJ, Kramer CM, Woodard PK, Shaw LJ, Yucel EK, Writing G: Appropriate Utilization of Cardiovascular Imaging A Methodology for the Development of Joint Criteria for the Appropriate Utilization of Cardiovascular Imaging by the American College of Cardiology Foundation and American College of Radiology. J Am Coll Radiol 2013, 10(6):456-463

6. Medicare Payment Advisory Commission (MedPAC): Report to the congress: Medicare payment policy March 2005. [http://www.medpac. gov/documents/Mar05_EntireReport.pdf]

7. Shaw LJ, Marwick TH, Zoghbi WA, Hundley WG, Kramer CM, Achenbach S, Dilsizian V, Kern MJ, Chandrashekhar Y, Narula J: Why all the focus on cardiac imaging? JACC Cardiovasc Imaging 2010, 3(7):789-794.

8. Medicare Payment Advisory Commission (MedPAC): Report to the congress: New approaches in Medicare. 2004 [http://www.medpac.gov/ documents/June04_Entire_Report.pdf]

9. Medicare Payment Advisory Commission (MedPAC): Report to the congress: Medicare payment policy March 2003. [http://www.medpac. gov/documents/Mar03_Entire_report.pdf]

10. Lucas FL, Sirovich BE, Gallagher PM, Siewers AE, Wennberg DE: Variation in cardiologists' propensity to test and treat: Is it associated with regional variation in utilization? Circ Cardiovasc Qual Outcomes 2010, 3:253-260.

11. The Dartmouth Atlas of Cardiovascular Health Care. In 115F. [http://www. dartmouthatlas.org/downloads/atlases/cardiovascular_atlas.pdf]

12. Brindis RG, Douglas PS, Hendel RC, Peterson ED, Wolk MJ, Allen JM, Patel MR, Raskin IE, Bateman TM, Cerqueira MD, Gibbons RJ, Gillam LD, Gillespie JA, Iskandrian AE, Jerome SD, Krumholz HM, Messer JV, Spertus JA, Stowers SA: ACCF/ASNC appropriateness criteria for single-photon emission computed tomography myocardial perfusion imaging (SPECT MPI): a report of the American College of Cardiology Foundation Quality Strategic Directions Committee Appropriateness Criteria Working Group and the American Society of Nuclear Cardiology endorsed by the American Heart Association. J Am Coll Cardiol 2005, 46(8):1587-1605. 
13. Douglas PS, Khandheria B, Stainback RF, Weissman NJ, Brindis RG, Patel MR, Alpert JS, Fitzgerald D, Heidenreich P, Martin ET, Messer JV, Miller AB, Picard $\mathrm{MH}$, Raggi $\mathrm{P}$, Reed KD, Rumsfeld JS, Steimle AE, Tonkovic R, Vijayaraghavan K, Yeon SB, Hendel RC, Peterson E, Wolk MJ, Allen JM: ACCF/ASE/ACEP/ ASNC/SCAI/SCCT/SCMR 2007 Appropriateness Criteria for Transthoracic and Transesophageal Echocardiography: A Report of the American College of Cardiology Foundation Quality Strategic Directions Committee Appropriateness Criteria Working Group, American Society of Echocardiography, American College of Emergency Physicians, American Society of Nuclear. J Am Coll Cardiol 2007, 50(2):187-204.

14. Douglas PS, Khandheria B, Stainback RF, Weissman NJ, Peterson ED, Hendel RC, Blaivas M, Des Prez RD, Gillam LD, Golash T, Hiratzka LF, Kussmaul WG, Labovitz AJ, Lindenfeld J, Masoudi FA, Mayo PH, Porembka D, Spertus JA, Wann LS, Wiegers SE, Brindis RG, Patel MR, Wolk MJ, Allen JM: ACCF/ASE/ACEP/AHA/ASNC/SCAI/SCCT/SCMR 2008 appropriateness criteria for stress echocardiography. Circulation 2008 , 117(11):1478-1497.

15. Douglas PS, Garcia MJ, Haines DE, Lai WW, Manning WJ, Patel AR, Picard MH, Polk DM, Ragosta M, Ward RP, Weiner RB, Bailey SR, Alagona P, Anderson JL, DeCara JM, Dolor RJ, Fazel R, Gillespie JA, Heidenreich PA, Leykum LK, Marine JE, Mishkel GJ, Pellikka PA, Raff GL, Vijayaraghavan K, Weissman NJ, Wu KC, Wolk MJ, Hendel RC, Kramer CM, et al:: ACCF/ASE/ AHA/ASNC/HFSA/HRS/SCAI/SCCM/SCCT/SCMR 2011 Appropriate Use Criteria for Echocardiography: A Report of the American College of Cardiology Foundation Appropriate Use Criteria Task Force, American Society of Echocardiography, American Heart Association, American Society of Nuclear Cardiology, Heart Failure Society of America, Heart Rhythm Society, Society for Cardiovascular Angiography and Interventions, Society of Critical Care Medicine, Society of Cardiovascular Computed Tomography, and Society for Cardiovascular Magnetic Resonance (vol 57, pg 1126, 2011). J Am Coll Cardiol 2011, 57(9):1167-1168.

16. Wolk MJ, Bailey SR, Doherty JU, Douglas PS, Hendel RC, Kramer CM, Min JK, Patel MR, Rosenbaum L, Shaw LJ, Stainback RF, Allen JM, Brindis RG Kramer CM, Shaw LJ, Cerqueira MD, Chen J, Dean LS, Fazel R, Hundley WG, Itchhaporia D, Kligfield P, Lockwood R, Marine JE, McCully RB, Messer JV, O'Gara PT, Shemin RJ, Wann LS, Wong JB, et al:: ACCF/AHA/ ASE/ASNC/HFSA/HRS/SCAI/SCCT/SCMR/STS 2013 Multimodality Appropriate Use Criteria for the Detection and Risk Assessment of Stable Ischemic Heart DiseaseA Report of the American College of Cardiology Foundation Appropriate Use Criteria Task Force, American Heart Association, American Society of Echocardiography, American Society of Nuclear Cardiology, Heart Failure Society of America, Heart Rhythm Society, Society for Cardiovascular Angiography and Interventions, Society of Cardiovascular Computed Tomography, Society for Cardiovascular Magnetic Resonance, and Society of Thoracic Surgeons. J Am Coll Cardiol 2014, 63(4):380-406

17. Aggarwal NR, Wuthiwaropas P, Karon BL, Miller FA, Pellikka PA: Application of the appropriateness criteria for echocardiography in an academic medical center. J Am Soc Echocardiogr 2010, 23(3):267-274.

18. Alqarqaz M, Koneru J, Mahan M, Ananthasubramaniam K: Applicability, limitations and downstream impact of echocardiography utilization based on the Appropriateness Use Criteria for transthoracic and transesophageal echocardiography. Int J Cardiovasc Imaging 2012, 28(8):1951-1958.

19. Bailey SA, Mosteanu I, Tietjen PA, Petrini JR, Alexander J, Keller AM: The use of transthoracic echocardiography and adherence to appropriate use criteria at a regional hospital. J Am Soc Echocardiogr 2012, 25(9):1015-1022.

20. Ballo P, Bandini F, Capecchi I, Chiodi L, Ferro G, Fortini A, Giuliani G, Landini G, Laureano R, Milli M, Nenci G, Pizzarelli F, Santoro GM, Vannelli P, Cappelletti C, Zuppiroli A, American College of Cardiology Foundation, American Society of Echocardiography: Application of 2011 American College of Cardiology Foundation/American Society of Echocardiography appropriateness use criteria in hospitalized patients referred for transthoracic echocardiography in a community setting. J Am Soc Echocardiogr 2012, 25(6):589-598.

21. Bhatia RS, Carne DM, Picard MH, Weiner RB: Comparison of the 2007 and 2011 appropriate use criteria for transesophageal echocardiography. J Am Soc Echocardiogr 2012, 25(11):1170-1175.
22. Bhatia RS, Carne DM, Picard MH, Weiner RB: Comparison of the 2007 and 2011 appropriate use criteria for transthoracic echocardiography in various clinical settings. J Am Soc Echocardiogr 2012, 25(11):1162-1169.

23. Bhatia RS, Milford CE, Picard MH, Weiner RB: An educational intervention reduces the rate of inappropriate echocardiograms on an inpatient medical service. JACC Cardiovasc Imaging 2013, 6(5):545-555.

24. Bhave NM, Mansour IN, Veronesi F, Razi RR, Lang RM, Ward RP: Use of a web-based application of the American College of Cardiology Foundation/ American Society of Echocardiography appropriateness use criteria for transthoracic echocardiography: A pilot study. J Am Soc Echocardiogr 2011, 24(3):271-276

25. Dharmarajan L, Hale TM, Velastegui Z, Castillo E, Kanna B: Utility of twodimensional echocardiography in pregnancy and post-partum period and impact on management in an inner city hospital. J Perinat Med 2009, 37(6):663-668.

26. Ghatak A, Pullatt R, Vyse S, Silverman DI: Appropriateness criteria are an imprecise measure for repeat echocardiograms. Echocardiography 2011, 28(2):131-135

27. Grewal GK, Klosterman TB, Shrestha K, Yarmohammadi H, Zurick AO, Varr BC, Tang WH, Lindsay BD, Klein AL: Indications for TEE before cardioversion for atrial fibrillation: implications for appropriateness criteria. JACC Cardiovasc Imaging 2012, 5(6):641-648.

28. Kirkpatrick JN, Ky B, Rahmouni HW, Chirinos JA, Farmer SA, Fields AV Ogbara J, Eberman KM, Ferrari VA, Silvestry FE, Keane MG, Opotowsky AR, Sutton MS, Wiegers SE: Application of Appropriateness Criteria in Outpatient Transthoracic Echocardiography. J Am Soc Echocardiogr 2009, 22(1):53-59.

29. Mansour IN, Razi RR, Bhave NM, Ward RP: Comparison of the updated 2011 appropriate use criteria for echocardiography to the original criteria for transthoracic, transesophageal, and stress echocardiography. J Am Soc Echocardiogr 2012, 25(11):1153-1161.

30. Martin NM, Picard MH: Use and appropriateness of transthoracic echocardiography in an academic medical center: a pilot observational study. J Am Soc Echocardiogr 2009, 22(1):48-52.

31. Matulevicius SA, Rohatgi A, Das SR, Price AL, Deluna A, Reimold SC: Appropriate use and clinical impact of transthoracic echocardiography. JAMA Intern Med 2013, 173(17):1600-1607.

32. Ogbara J, Logani S, Ky B, Chirinos JA, Silvestry FE, Eberman K, Moss JD, Ferrari VA, Keane MG, Sutton MSJ, Wiegers SE, Kirkpatrick JN: The Utility of Prescreening Transesophageal Echocardiograms: A Prospective Study. Echocardiography-J Cardiovasc Ultrasound Allied Tech 2011, 28(7):767-773.

33. Parikh PB, Asheld J, Kort S: Does the revised appropriate use criteria for echocardiography represent an improvement over the initial criteria? A comparison between the 2011 and the 2007 appropriateness use criteria for echocardiography. J Am Soc Echocardiogr 2012, 25(2):228-233.

34. Patil HR, Coggins TR, Kusnetzky LL, Main ML: Evaluation of appropriate use of transthoracic echocardiography in 1,820 consecutive patients using the 2011 revised appropriate use criteria for echocardiography. Am J Cardiol 2012, 109(12):1814-1817.

35. Rahimi AR, York M, Gheewala N, Markson L, Hauser TH, Manning WJ: Trends in outpatient transthoracic echocardiography: impact of appropriateness criteria publication. Am J Med 2011, 124(8):740-746.

36. Rao G, Sajnani N, Kusnetzky LL, Main ML: Appropriate use of transthoracic echocardiography. Am J Cardiol 2010, 105(11):1640-1642.

37. Rao GA, Sajnani NV, Kusnetzky LL, Main ML: Appropriate utilization of transesophageal echocardiography. Am J Cardiol 2009, 103(5):727-729.

38. Silverman GP, Vyse S, Silverman DI: Inappropriately Ordered Echocardiograms Are Related to Socioeconomic Status. Am J Med Qual 2012, 27(6):487-493.

39. Ward RP, Mansour IN, Lemieux N, Gera N, Mehta R, Lang RM: Prospective evaluation of the clinical application of the American College of Cardiology Foundation/American Society of Echocardiography Appropriateness Criteria for transthoracic echocardiography. JACC Cardiovasc Imaging 2008, 1(5):663-671.

40. Willens HJ, Gómez-Marín O, Heldman A, Chakko S, Postel C, Hasan T, Mohammed F: Adherence to Appropriateness Criteria for Transthoracic Echocardiography: Comparisons Between a Regional Department of Veterans Affairs Health Care System and Academic Practice and Between Physicians and Mid-Level Providers. J Am Soc Echocardiogr 2009, 22(7):793-799. 
41. Willens HJ, Hendel RC, Inhaber FR, Chakko SC, Postel C, Hasan T, Mohammed F: Appropriateness use criteria for transthoracic echocardiography: relationship with radiology benefit managers preauthorization determination and comparison of the new (2010) criteria to the original (2007) criteria. Am Heart J 2011, 162(4):772-779.

42. Bhattacharyya S, Kamperidis V, Nalin Shah B, Roussin I, Chahal N, Li W, Khattar R, Senior R: Clinical utility and prognostic value of appropriateness criteria in stress echocardiography for the evaluation of valvular heart disease. JACC Cardiovasc Imaging 2013, 6(9):987-992.

43. Schmitz L, Mori N, Khandheria BK, Gupta A: Appropriateness criteria for stress echocardiography in patients with acute chest pain: Are we choosing wisely? Int J Cardiol 2013, 165(2):387-388.

44. Cheitlin MD, Armstrong WF, Aurigemma GP, Beller GA, Bierman FZ, Davis JL, Douglas PS, Faxon DP, Gillam LD, Kimball TR, Kussmaul WG, Pearlman AS, Philbrick JT, Rakowski H, Thys DM, Antman EM, Smith JSC, Alpert JS, Gregoratos G, Anderson JL, Hiratzka LF, Hunt SA, Fuster V, Jacobs AK, Gibbons RJ, Russell RO: ACC/AHA/ASE 2003 Guideline Update for the Clinical Application of Echocardiography: Summary Article: A Report of the American College of Cardiology/American Heart Association Task Force on Practice Guidelines (ACC/AHA/ASE Committee to Update the 1997 Guidelines for the Clinical Application of Echocardiography). Circulation 2003, 108(9):1146-1162.

45. Fonseca R, Negishi K, Marwick T: Nothing has changed after six years of appropriate use criteria. A systematic review of appropriate use in transthoracic and transesophageal echocardiography [abstract]. J Am SoC Echocariogr 2014, 27:B96.

46. Gibbons RJ, Askew JW, Hodge D, Kaping B, Carryer DJ, Miller T: Appropriate use criteria for stress single-photon emission computed tomography sestamibi studies: A quality improvement project. Circulation 2011, 123(5):499-503.

47. Willens HJ, Nelson K, Hendel RC: Appropriate use criteria for stress echocardiography: Impact of updated criteria on appropriateness ratings, correlation with pre-authorization guidelines, and effect of temporal trends and an educational initiative on utilization. JACC Cardiovasc Imaging 2013, 6(3):297-309.

48. Mitchell JM, LaGalia RR: Controlling the Escalating Use of Advanced Imaging: The Role of Radiology Benefit Management Programs. Med Care Res Rev 2009, 66(3):339-351.

doi:10.1186/1476-7120-12-22

Cite this article as: Fonseca and Marwick: How I do it: judging

appropriateness for TTE and TEE. Cardiovascular Ultrasound 2014 12:22.

\section{Submit your next manuscript to BioMed Central and take full advantage of:}

- Convenient online submission

- Thorough peer review

- No space constraints or color figure charges

- Immediate publication on acceptance

- Inclusion in PubMed, CAS, Scopus and Google Scholar

- Research which is freely available for redistribution 